\title{
Corrigendum: Linguistic influence on mathematical development is specific rather than pervasive: revisiting the Chinese Number Advantage in Chinese and English children
}

\author{
Winifred Mark ${ }^{1}$ and Ann Dowker ${ }^{2 *}$ \\ ${ }^{1}$ Department of Psychology, University of Hong Kong, Hong Kong, China, ${ }^{2}$ Department of Experimental Psychology, Oxford \\ University, Oxford, UK
}

Keywords: linguistic transparency, counting system, arithmetic, cross-cultural, Chinese Number Advantage

\section{A corrigendum on}

\section{OPEN ACCESS}

Edited and reviewed by:

Yvette Renee Harris,

Miami University, USA

*Correspondence:

Ann Dowker

ann.dowker@psy.ox.ac.uk

Specialty section: This article was submitted to Developmental Psychology, a section of the journal

Frontiers in Psychology

Received: 20 February 2016 Accepted: 24 February 2016

Published: 16 March 2016

Citation:

Mark W and Dowker A (2016) Corrigendum: Linguistic influence on mathematical development is specific

rather than pervasive: revisiting the Chinese Number Advantage in Chinese and English children Front. Psychol. 7:342. doi: 10.3389/fpsyg.2016.00342
Linguistic influence on mathematical development is specific rather than pervasive: revisiting the Chinese Number Advantage in Chinese and English children by Mark, W., and Dowker, A. (2015). Front. Psychol. 6:203. doi: 10.3389/fpsyg.2015.00203

Due to an oversight, the two sentences preceding the final sentence in the abstract should be changed to read: Results indicated that students in HK-C were better at counting backward than those in HKE, who were in turn better than the UK students. However, there was no statistical difference in counting forward or place value understanding. Children in both Hong Kong schools performed better at the arithmetic test than the UK children. Among the older group, the HK-C children performed better on the arithmetic test than the HK-E children, but no such difference was found in the younger group.

The authors apologize for this mistake.

This error does not change the scientific conclusions of the article in any way.

\section{AUTHOR CONTRIBUTIONS}

All authors listed, have made substantial, direct and intellectual contribution to the work, and approved it for publication.

Conflict of Interest Statement: The authors declare that the research was conducted in the absence of any commercial or financial relationships that could be construed as a potential conflict of interest.

Copyright (c) 2016 Mark and Dowker. This is an open-access article distributed under the terms of the Creative Commons Attribution License (CC BY). The use, distribution or reproduction in other forums is permitted, provided the original author(s) or licensor are credited and that the original publication in this journal is cited, in accordance with accepted academic practice. No use, distribution or reproduction is permitted which does not comply with these terms. 